\title{
EVALUATION OF FREE RADICAL SCAVENGING ACTIVITY OF MIMOSA PUDICA THORNS
}

\author{
LAKSHMIBAI R ${ }^{1 *}$, AMIRTHAM D ${ }^{2}$
}

${ }^{1}$ Research Scholar, Research and Development Centre, Bharathiar University, Coimbatore, Tamil Nadu, India. ${ }^{2}$ Department of Food and Agricultural Process Engineering, Agricultural Engineering College and Research Institute, TNAU, Coimbatore, Tamil Nadu, India. Email: rlakshb@gmail.com is the mail

Received: 21 May 2018, Revised and Accepted: 03 July 2018

\section{ABSTRACT}

Objective: Mimosa pudica is a traditional medicinal plant. The natural antioxidant compounds from plants mop up the free radicals causing cell damage and maintain the biological systems. The aim of the present study is to evaluate the free radical scavenging potential of the ethanolic and aqueous thorn extracts of M. pudica.

Methods: The ethanolic and aqueous thorn extracts of M. pudica were analyzed for the phytochemicals and for free radical scavenging activity by 1,1 diphenyl 1-2-picric hydrazine (DPPH), 2, 2'-azinobis-3-ethylbenzothiazoline-6-sulfonic acid (ABTS), and nitric oxide free radical scavenging method.

Results: Flavonoids, saponins, glycosides, alkaloids, terpenoids, and coumarins were the phytoconstituents revealed in ethanolic and aqueous thorn extracts of M. pudica. At $250 \mu \mathrm{g} / \mathrm{mL}$ concentrations, aqueous thorn extracts of $M$. pudica exhibited $73.41 \%$ radical scavenging activity by DPPH method and $26.10 \%$ inhibition by nitric oxide free radical scavenging method. However, the ethanolic extracts of M. pudica thorns exhibited $73.35 \%$ inhibition by ABTS free radical scavenging method at $250 \mu \mathrm{g} / \mathrm{mL}$ concentrations.

Conclusion: The results obtained suggest that the plant extracts from M. pudica could serve as a potential source of antioxidant in slowing down the process of aging and age-related or oxidative stress-related degenerative diseases. Moreover, the isolation of bioactive principle responsible for the antioxidant activity and formulation of novel therapeutic agents can be further studied.

Keywords: Mimosa pudica, Free radical scavenging, Phytoconstituents, Bioactive principle.

(C) 2018 The Authors. Published by Innovare Academic Sciences Pvt Ltd. This is an open access article under the CC BY license (http://creativecommons. org/licenses/by/4. 0/) DOI: http://dx.doi.org/10.22159/ajpcr.2018.v11i11.27426

\section{INTRODUCTION}

Plants are the largest reservoir of the bioactive principles which have a long history of use in modern medicine and in certain systems of traditional medicine. Plant-derived compounds form the basis for pharmaceutical drugs and phytotherapy [1]. Antioxidants react through free radical or molecular oxygen quenching, being capable of either delaying or inhibiting the oxidation processes which occur under the influence of molecular oxygen or reactive oxygen species [2]. Many factors are responsible for inducing oxidative stress and enhancing the production of free radicals such as radiation or exposure to heavy metals and xenobiotics [3]. Antioxidants are responsible for the defense mechanism of the organism against the pathologies associated to the attack of free radicals, and thus, the intake of plant-derived antioxidants is involved in the prevention of degenerative diseases caused by oxidative stress, such as cancer, Parkinson, Alzheimer, or atherosclerosis [2]. The antioxidant activities of medicinal plants may be explained by the presence of phenolic compounds, containing the hydroxyl group that confers the hydrogen-donating ability [4].

Mimosa pudica L. has been used widely in traditional medicine [5]. Other names of M. pudica are touch me not or sensitive plant, and it is usually a short prickly plant with its branches growing close to the ground [6]. M. pudica belongs to the family Fabaceae and the Mimosoideae subfamily. It invites the attention of researchers worldwide for its pharmacological activities such as antidiabetic, antitoxin, antihepatotoxic, and wound healing activities. It is reported to contain alkaloid, glycoside, flavonoid, and tannin [7]. M. pudica contains an alkaloid called mimosine, which has been found to have potent antiproliferative and apoptotic effects [8]. It is used in the treatment of biliousness, leprosy, dysentery, vaginal and uterine complaints, inflammations, burning sensation, fatigue, asthma, leucoderma, blood diseases, etc. [9]. And also, M. pudica has antidepressant, anticonvulsant, and antivenom activities and diuretic effect [10].
In the present study, the phytochemicals were screened, and the free radical scavenging activity of the ethanolic and aqueous thorn extracts of M. pudica was analyzed.

\section{METHODS}

\section{Collection and identification of plant material}

The M. pudica plant was collected from Thirukalikundram, Kanchipuram District. The plant was authenticated by Dr. Sasikala Ethirajulu and Dr. Jega Jothi Pandian, Siddha Central Research Institute, Arignar Anna Government Hospital campus, Arumbakkam, Chennai. M. pudica thorns were thoroughly washed with fresh water. Then, the thorns were shade dried at room temperature, were powdered using pulverizer, and were used for extraction.

\section{Preparation of ethanolic and aqueous thorn extracts} Ethanolic thorn extract

Successive extractions were made using $20 \mathrm{~g}$ of the powdered thorns of M. pudica with $250 \mathrm{~mL}$ of ethanol using Soxhlet extractor for 15 refluxes. The extract was condensed using rotary evaporator. Then, the thorn extract was labeled and stored at $5^{\circ} \mathrm{C}$ for further use.

\section{Aqueous thorn extract}

$20 \mathrm{~g}$ of the powdered thorns of M. pudica were soaked in $250 \mathrm{~mL}$ double-distilled water and kept in an orbital shaker for $24 \mathrm{~h}$ in a closed Erlenmeyer flask for continuous agitation. Filtration of extract was needed to be done using Whatman No.1 filter paper. Using rotary vacuum evaporator, the solvent from the extract was removed. The extract obtained was labeled and then stored at $5^{\circ} \mathrm{C}$ for further use.

\section{Phytochemical screening}

Qualitative phytochemical screening of the thorn extracts of $M$. pudica was done using the standard methods $[11,12]$. Flavonoids, steroids, 
tannins, saponins, glycosides, alkaloids, terpenoids, anthraquinones, and coumarins were the phytochemicals screened.

Antioxidant activity using 1, 1 diphenyl 1-2-picric hydrazine (DPPH) free radical scavenging activity

In vitro antioxidant activity was assessed by DPPH radical scavenging activity [13]. In the control tube (C), $0.1 \mathrm{~mL}$ of methanol was taken and $0.1 \mathrm{~mL}$ of varying concentrations $(50-250 \mu \mathrm{g} / \mathrm{mL})$ of ethanolic and aqueous thorn extracts of M. pudica was added in the tube (T), respectively. $2.0 \mathrm{~mL}$ of $0.1 \mathrm{mM}$ of methanolic DPPH was added to all the tubes which include control, test, and standard. The standard used throughout the experiment was ascorbic acid. The tubes were incubated in the dark for $20 \mathrm{~min}$ and then were read at $517 \mathrm{~nm}$ by spectrophotometer. The percentage of inhibition was obtained by making use of the following formula and expressed as percentage scavenging of DPPH radical [14]. All the tests were carried out in triplicates.

$\%$ DPPH inhibition $=\frac{\text { Absorbance of control }- \text { Absorbance of test }}{\text { Absorbance of control }} \times 100$

Antioxidant activity using 2, 2'-azinobis-3-ethylbenzothiazoline-6sulfonic acid radical cation (ABTS) free radical scavenging activity ABTS $^{*+}$ decolorization assay was used to determine the free radical scavenging activity [15]. ABTS radical cation was obtained by the reaction between $7 \mathrm{mM}$ ABTS in water and $2.45 \mathrm{mM}$ potassium persulfate (final concentration) and was stored for $12-16 \mathrm{~h}$ in the dark at room temperature before use. $\mathrm{ABTS}^{*+}$ solution was then diluted with absolute ethanol to obtain an absorbance of $0.70( \pm 0.02)$ at $734 \mathrm{~nm}$. Reagent blank reading was taken $\left(A_{0}\right) .2 .0 \mathrm{~mL}$ of diluted $\mathrm{ABTS}^{*+}$ solution $(A 734 \mathrm{~nm}=0.70( \pm 0.02))$ was added to $20 \mu \mathrm{L}$ of varying concentrations $(50-250 \mu \mathrm{g} / \mathrm{mL})$ of the ethanolic and aqueous thorn extracts of $M$. pudica, and the absorbance was measured exactly 6 min after initial mixing $\left(A_{t}\right)$. Appropriate solvent blanks were run in each assay. Ascorbic acid was regarded as standard. The tests were replicated 3 times. Absorbance was measured at $734 \mathrm{~nm}$. Using the formula, the scavenging activity was calculated as percentage inhibition.

$\%$ Inhibition $=\left[\left(A_{C(0)}-A_{A(t)}\right) / A_{C(0)}\right] \times 100$

Where $A_{C(0)}$ is the absorbance of the control at $\mathrm{t}=0 \mathrm{~min}$ and $A_{A(t)}$ is the absorbance of the sample (thorn extracts) at $\mathrm{t}=6 \mathrm{~min}$.

Nitric oxide free radical scavenging activity

Nitric oxide generated from sodium nitroprusside in aqueous solution at physiological pH was measured by Griess-Ilosvay reaction $[16,17]$. The reaction mixture of $3 \mathrm{~mL}$ containing $2 \mathrm{~mL}$ sodium nitroprusside $(10 \mathrm{~mm})$ in $0.5 \mathrm{~mL}$ phosphate buffer saline $(0.025 \mathrm{M}$, and $\mathrm{pH} 7.4)$ and $0.5 \mathrm{~mL}$ of the ethanolic and aqueous thorn extracts of $M$. pudica of various concentrations $(50-250 \mu \mathrm{g} / \mathrm{mL})$ was incubated at $25^{\circ} \mathrm{C}$ for $150 \mathrm{~min}$. A control experiment without the sample but with an equivalent amount of buffer was made in an identical manner. $1.5 \mathrm{~mL}$ of the reaction mixture was removed after incubation, and $1.5 \mathrm{~mL}$ of the Griess reagent (1\% sulfanilamide, $2 \%$ orthophosphoric acid, and $0.1 \%$ napthylethylenediamine dihydrochloride) was added. Using ascorbic acid as standard, the same procedure was conducted. The absorbance of the chromophore formed was read at $546 \mathrm{~nm}$. Percentage inhibition of nitric oxide scavenging activity was estimated using the formula. All the tests were performed out in triplicates.

$\%$ inhibition $=\frac{\text { Absorbance of control }- \text { Absorbance of test }}{\text { Absorbance of control }} \times 100$

Statistical analysis

The samples were taken in triplicates and analyzed, and the results were reported in mean \pm standard deviation (SD).

\section{RESULTS AND DISCUSSION}

\section{Phytochemical analysis}

The phytochemicals such as flavonoids, saponins, glycosides, alkaloids, terpenoids, and coumarins were present in the ethanolic and aqueous
Table 1: Phytochemical analysis of thorn extracts of $M$. pudica

\begin{tabular}{lll}
\hline Phytochemicals & $\begin{array}{l}\text { Ethanolic thorn } \\
\text { extracts }\end{array}$ & $\begin{array}{l}\text { Aqueous thorn } \\
\text { extracts }\end{array}$ \\
\hline Flavonoids & + & + \\
Steroids & + & - \\
Tannins & - & + \\
Saponins & + & + \\
Glycosides & + & + \\
Alkaloids & + & + \\
Terpenoids & + & + \\
Anthraquinones & - & - \\
Coumarins & + & + \\
\hline
\end{tabular}

+: Present, -: Absent, M. pudica: Mimosa pudica

Table 2: Percentage inhibition by DPPH free radical scavenging method

\begin{tabular}{lll}
\hline $\begin{array}{l}\text { Concentration } \\
(\mu \mathbf{g} / \mathbf{m L})\end{array}$ & $\begin{array}{l}\text { Ethanolic thorn } \\
\text { extracts of } \boldsymbol{M} \text {. pudica }\end{array}$ & $\begin{array}{l}\text { Aqueous thorn } \\
\text { extracts of } \boldsymbol{M} \text {. } \text { pudica }\end{array}$ \\
\hline 50 & $21.24 \pm 0.36$ & $53.64 \pm 0.41$ \\
100 & $22.8 \pm 0.28$ & $55.41 \pm 0.41$ \\
150 & $36.3 \pm 0.38$ & $60.68 \pm 0.23$ \\
200 & $46.39 \pm 0.42$ & $62.35 \pm 0.40$ \\
250 & $60.59 \pm 0.41$ & $73.41 \pm 0.26$ \\
\hline
\end{tabular}

Data are mean \pm SD values; $\mathrm{n}=3$, SD: Standard deviation, M. pudica: Mimosa pudica, DPPH: 1, 1 diphenyl 1-2-picric hydrazine

Table 3: Percentage inhibition by ABTS free radical scavenging method

\begin{tabular}{lll}
\hline $\begin{array}{l}\text { Concentration } \\
(\mu \mathbf{g} / \mathbf{m L})\end{array}$ & $\begin{array}{l}\text { Ethanolic thorn } \\
\text { extracts of } \boldsymbol{M} \text {. pudica }\end{array}$ & $\begin{array}{l}\text { Aqueous thorn } \\
\text { extracts of } \boldsymbol{M} \text {. } \text { pudica }\end{array}$ \\
\hline 50 & $50.23 \pm 0.61$ & $9.28 \pm 0.27$ \\
100 & $56.18 \pm 0.29$ & $14.61 \pm 0.35$ \\
150 & $59.52 \pm 0.52$ & $16.38 \pm 0.47$ \\
200 & $65.24 \pm 0.32$ & $20.86 \pm 0.20$ \\
250 & $73.35 \pm 0.54$ & $25.69 \pm 0.33$ \\
\hline
\end{tabular}

Data are mean \pm SD values; $n=3$, SD: Standard deviation, M. pudica: Mimosa pudica, ABTS: 2, 2'-azinobis-3-ethylbenzothiazoline-6-sulfonic acid

Table 4: Percentage inhibition by nitric oxide free radical scavenging method

\begin{tabular}{lll}
\hline $\begin{array}{l}\text { Concentration } \\
(\mu \mathrm{g} / \mathrm{mL})\end{array}$ & $\begin{array}{l}\text { Ethanolic thorn } \\
\text { extracts of } \boldsymbol{M} \text {. pudica }\end{array}$ & $\begin{array}{l}\text { Aqueous thorn } \\
\text { extracts of } \boldsymbol{M} \text {. } \text { pudica }\end{array}$ \\
\hline 50 & $3.74 \pm 0.26$ & $13.51 \pm 0.44$ \\
100 & $6.47 \pm 0.43$ & $16.60 \pm 0.33$ \\
150 & $10.28 \pm 0.32$ & $20.8 \pm 0.52$ \\
200 & $15.27 \pm 0.44$ & $22.08 \pm 0.27$ \\
250 & $17.94 \pm 0.26$ & $26.10 \pm 0.22$ \\
\hline
\end{tabular}

Data are mean \pm SD values; $\mathrm{n}=3$, SD: Standard deviation, M. pudica: Mimosa pudica

thorn extracts of $M$. pudica [Table 1]. In the ethanolic thorn extracts of $M$. pudica, steroids were present. Tannin was present in the aqueous thorn extracts of $M$. pudica. It was reported in a study that the preliminary phytochemical screening of the $M$. pudica leaf extract showed the presence of bioactive components such as terpenoids, flavonoids, glycosides, alkaloids, quinines, phenols, tannins, saponins, and coumarins [18]. Studies suggest that the preliminary phytochemical analysis of the chloroform extract of $M$. pudica Linn. leaves revealed the presence of phytoconstituents such as steroids, flavonoids, glycosides, alkaloids, and phenolic compounds [19]. It is also supported in a study that preliminary phytochemical screening of the ethanolic extracts of M. pudica Linn. revealed the presence of alkaloids, flavonoids, saponins, 
terpenoids, tannins, and phenolics [20] The experimental results of previous studies suggest that the biologically active phytoconstituents such as flavonoids, glycosides and alkaloids present in the methanolic extract of plant $M$. pudica may be responsible for the significant hepatoprotective activity [21] and also supported by a study that the phytochemical analysis of the crude ethanolic extracts of leaves and roots of $M$. pudica indicated the presence of tannins, proteins, and steroids [22]. The results of the previous study suggested that phenolic and flavonoids may be the major contributors for the antioxidant activity [23].

\section{Antioxidant activity by DPPH free radical scavenging method}

To determine the antioxidant activity of drugs obtained from plants, DPPH method is used commonly. The aqueous thorn extracts exhibited higher values than the ethanolic thorn extracts of $M$. pudica [Table 2]. $73.41 \%$ radical scavenging activity was obtained at $250 \mu \mathrm{g} / \mathrm{mL}$ concentration of aqueous thorn extracts. The $\mathrm{IC}_{50}$ value of ethanolic and aqueous thorn extracts of M. pudica was found to be $211.25 \pm 0.51 \mu \mathrm{g} / \mathrm{mL}$ and $30.56 \pm 0.41 \mu \mathrm{g} / \mathrm{mL}$, respectively. IC ${ }_{50}$ value of aqueous thorn extracts is lesser than the ethanolic thorn extracts of $M$. pudica, proving that aqueous thorn extracts have higher antioxidant activity. The hydroalcoholic extract of M. pudica Linn. (Mimosaceae) and L-Mimosine proved to have a significant antioxidant and anticancer activity [24]. It was reported in a study that the in vitro antioxidant activity indicates that petroleum ether leaf extract of M. pudica showed maximum antioxidant activity [25]. Another study suggests that the methanolic crude extracts of $M$. pudica leaves showed moderate antioxidant activity [26]. The ethanolic extract of M. pudica roots showed a very good antioxidant activity [27]. It was also found in previous studies that the whole plant, stems, leaves, and seeds of $M$. pudica Linn. showed strong antioxidant capacity, and moreover, the antioxidant activity of M. pudica Linn. in vitro could be related to the high concentration of flavonoids and phenolics [28]. A study reported that the methanol crude extract of the aerial parts of M. pudica showed moderate antioxidant activity using the DPPH free radical scavenging assay [29].

\section{Antioxidant activity by ABTS free radical scavenging method}

Among the ethanolic and aqueous thorn extracts, the ethanolic thorn extracts of M. pudica showed higher values [Table 3]. At $250 \mu \mathrm{g} / \mathrm{mL}$ concentrations of ethanolic thorn extracts of $M$. pudica, the radical scavenging activity was found to be $73.35 \%$. Ethanolic thorn extracts of $M$. pudica exhibited IC ${ }_{50}$ value of $51.28 \pm 4.31 \mu \mathrm{g} / \mathrm{mL}$, and the aqueous thorn extracts exhibited IC $\mathrm{IC}_{50}$ value of $567.84 \pm 11.71 \mu \mathrm{g} / \mathrm{mL}$. The results of previous studies revealed that M. pudica leaves exhibited higher antioxidant activity by ABTS radical scavenging activity [30]. It was suggested in a study that the methanolic extracts of $M$. pudica were having maximum antioxidant efficiency in DPPH, ABTS, and FRAP assays [31]. The methanolic extracts of Mimosa hamata stem exhibited greatest antioxidant activity with DPPH and ABTS methods [32]. It was reported in a study that water extracts from M. pudica exhibited prominent ABTS radical scavenging activities [33].

\section{Nitric oxide free radical scavenging method}

Aqueous thorn extracts of $M$. pudica unveiled higher values than its ethanolic thorn extracts, using nitric oxide radical scavenging method [Table 4]. At $250 \mu \mathrm{g} / \mathrm{mL}$ concentrations of aqueous thorn extracts, $26.10 \%$ inhibition was resulted. The $\mathrm{IC}_{50}$ values of the aqueous thorn extracts of $M$. pudica were found to be lesser $(642.68 \pm 20.82 \mu \mathrm{g} / \mathrm{mL})$ than the respective ethanolic extracts $(677.09 \pm 17.97 \mu \mathrm{g} / \mathrm{mL})$. A study suggested that the hexane extracts of M. pudica Linn. revealed the significant scavenging effect on DPPH, hydroxyl, nitric oxide, and superoxide radicals [34]. It was reported in a study that the ethanolic extract of M. pudica (Mimosaceae) exhibited a significant inhibition in nitric oxide and DPPH free radical formation [35]. The ethyl acetate fraction of M. pudica exhibited high reduction capacity and powerful free radical scavenging against DPPH and NO radical inhibition assay [36]. Previous studies revealed that the chloroform extract of M. pudica Linn. leaves showed a significant antioxidant activity against free radical scavenging by DPPH, nitric oxide, superoxide dismutase, and reducing ability. Moreover, it was also reported that the in vitro antioxidant activity was due to the antioxidant principle phenolic compounds and flavonoids [19]. In earlier studies, it is reported that the nitric oxide activity may be due to the presence of antioxidant polyphenolic molecules [37].

\section{CONCLUSION}

The results of phytochemical analysis revealed the presence of flavonoids, saponins, glycosides, alkaloids, terpenoids, and coumarins in the ethanolic and aqueous thorn extracts of M. pudica. The aqueous thorn extracts of M. pudica exhibited higher antioxidant activity by DPPH and nitric oxide free radical scavenging method, whereas the ethanolic extracts of $M$. pudica thorns exhibited higher antioxidant activity by ABTS free radical scavenging method. The bioactive principles in the extracts of M. pudica might have contributed the free radical scavenging activity. Hence, the current study gives a roadmap for isolating and characterizing the potential compound from the extracts of $M$. pudica for therapeutic applications.

\section{ACKNOWLEDGMENT}

The authors are grateful to members who were helpful during plant collection and analysis.

\section{AUTHORS' CONTRIBUTIONS}

Mrs. R. Lakshmibai performed the experiment and wrote the manuscript, and Dr. D. Amirtham supervised the progress of the work and involved in the corrections of the manuscript.

\section{CONFLICTS OF INTEREST}

The authors confirm that there is no conflict of interest.

\section{REFERENCES}

1. Sahu PR, Khalkho AS, Kumari S, Alam S. Studies on ethnomedicinal uses and formulation of herbal drugs from medicinal plants of Ranchi district-a survey. Am J Ethnomed 2015;2:284-96.

2. Pisoschi AM, Negulescu GP. Methods for total antioxidant activity determination: A review. Biochem Anal Biochem 2011;1:1-10.

3. Shinde DB, Koratkar SS, Sharma NE, Shitole AA. Antioxidant activity and antiproliferative action of methanolic extract of liquorice (Glycyrrhiza glabra) in HepG2 cell line. Int J Pharm Pharm Sci 2016;8:293-8.

4. Narayanaswamy N, Balakrishnan KP. Evaluation of some medicinal plants for their antioxidant properties. Int $\mathrm{J}$ PharmTech Res 2011;3:381-5.

5. Aziz U, Akther R, Shahriar M, Bhuiyan MA. In vivo pharmacological investigation of Mimosa pudica L. Int J Pharm Pharm Sci 2014;6:66-9.

6. Varnika S, Ashish S, Imran A. A review on ethnomedical and traditional uses of Mimosa pudica (Chui-mui). Int Res J Pharm 2012;3:41-4.

7. Joseph B, George J, Mohan J. Pharmacology and traditional uses of Mimosa pudica. Int J Pharm Sci Drug Res 2013;5:41-4.

8. Azmi L, Singh MK, Akhtar AK. Pharmacological and biological overview on Mimosa pudica Linn. Int J Pharm Life Sci 2011;2:1226-34.

9. Chauhan BS, Johnson DE. Germination, emergence, and dormancy of Mimosa pudica. Weed Biol Manage 2009;9:38-45.

10. Ahmad H, Sehgal S, Mishra A, Gupta R. Mimosa pudica L.(Laajvanti): An overview. Pharmacog Rev 2012;6:115-24.

11. Harborne J. Phytochemical Methods, a Guide to Modern Techniques of Plant Analysis, JB Harborne. London. GB: Chapman; 1973.

12. Trease GE, Evans WC. A Physician's Guide to Herbal Medicine. $13^{\text {th }}$ ed. London: Pharmacognosy, Bailliere Tindall; 1989. p. 176-80.

13. Von Gadow A, Joubert E, Hansmann CF. Comparison of the antioxidant activity of aspalathin with that of other plant phenols of rooibos tea (Aspalathus linearis), $\alpha$-tocopherol, BHT, and BHA. J Agric Food Chem 1997;45:632-8.

14. Yen GC, Duh PD. Scavenging effect of methanolic extracts of peanut hulls on free-radical and active-oxygen species. J Agric Food Chem 1994;42:629-32.

15. Re R, Pellegrini N, Proteggente A, Pannala A, Yang M, Rice-Evans C. Antioxidant activity applying an improved ABTS radical cation 
decolorization assay. Free Radical Biol Med 1999;26:1231-7.

16. Garrat DC. The Quantitative Analysis of Drugs. Japan: Chapman and Hall Ltd.; 1964. p. 3, 456-8.

17. Marcocci L, Maguire JJ, Droylefaix MT, Packer L. The nitric oxidescavenging properties of Ginkgo biloba extract EGb 761. Biochem Biophys Res Commun 1994;201:748-55.

18. Gandhiraja N, Sriram S, Meenaa V, Srilakshmi JK, Sasikumar C, Rajeswari R. Phytochemical screening and antimicrobial activity of the plant extracts of Mimosa pudica L. against selected microbes. Ethnobotanical Leaflets 2009;13:618-24.

19. Rajendran R, Hemachander R, Ezhilarasan T, Keerthana C, Saroja DL, Saichand KV, et al. Phytochemical analysis and in-vitro antioxidant activity of Mimosa pudica Lin., leaves. Res J Pharm Technol 2010;3:551-5

20. Sharma MC, Sharma S. Phytochemical and pharmacological screening of combined Mimosa pudica Linn and Tridax procumbens for in vitro antimicrobial activity. Int J Microbiol Res 2010;1:171-4.

21. Rajendran R, Hemalatha S, Akasakalai K, Krishna CH, Sohil B, Vittal R, et al. Hepatoprotective activity of Mimosa pudica leaves against carbontetrachloride induced toxicity. J Nat Prod 2009;2:116-22.

22. Ranjan RK, Kumar MS, Seethalakshmi I, Rao MR. Phytochemical analysis of leaves and roots of Mimosa pudica collected from Kalingavaram, Tamil Nadu. J Chem Pharm Res 2013;5:53-5.

23. Figueroa LA, Navarro LB, Verá MP, Petricevich VL. Antioxidant activity, total phenolic and flavonoids contents and cytotoxicity evaluation of Bougainvillea xbuttiana. Int J Pharm Pharm Sci 2014;6:497-502.

24. Parmar F, Kushawaha N, Highland H, George LB. In vitro antioxidant and anticancer activity of Mimosa pudica linn extract and L-mimosine on Lymphoma daudi cells. Int J Pharm Pharm Sci 2015;7:100-4.

25. Ahmed T,Akter R, SharifS, Shahriar M, Bhuiyan MA. In vitro antioxidant activities and in vivo anti-nociceptive and neuropharmacological activities of Mimosa pudica. Int J Pharm 2014:4:70-8.

26. Das K, Yasin M, Mahbub NU, Islam MS, Mahbuba N. Evaluation of antioxidant and cytotoxic activity of methanolic extract of Mimosa pudica leaves. Pharm Innov 2014;3:32-6.

27. Nour AH, Khan M, Sulaiman AZ, Batool T, Nour AH, Khan MM, et al. In vitro anti-acetyl cholinesterase and antioxidant activity of selected Malaysian plants. Asian J Pharm Clin Res 2014;7:93-7.

28. Zhang J, Yuan K, Zhou WL, Zhou J, Yang P. Studies on the active components and antioxidant activities of the extracts of Mimosa pudica Linn. from Southern China. Pharmacogn Mag 2011;7:35-9.

29. Chowdhury SA, Islam J, Rahaman MM, Rahman MM, Rumzhum NN, Sultana R, et al. Cytotoxicity, antimicrobial and antioxidant studies of the different plant parts of Mimosa pudica. Stamford. J Pharm Sci $2008 ; 1: 80-4$

30. Gruyal GA. Selected ethnomedicinal plants of northern surigao del Sur: Their antioxidant activities in terms of total phenolics, ABTS radical cation decolorization power, and ferric reducing ability. World Acad Sci Eng Technol Int J Nutr Food Eng 2015;9:981-4.

31. Guha G, Rajkumar V, Mathew L, Kumar RA. The antioxidant and DNA protection potential of Indian tribal medicinal plants. Turk J Biol 2011;35:233-42.

32. Singh R, Chandarana M. Jasrai YT. Determination of the phenolic and flavonoid contents in Mimosa hamata as well as their radical scavenging activity. Int J Pharmacog Phytochem 2013;28:1121-6.

33. Chimsook T. Bioactivities of Mimosa pudica and Phyllanthus niruri crude extracts collected from the locality of Chaiyaphum, Thailand. Adv Mater Res 2014;1044:12-5.

34. Almalki MA. In-vitro antioxidant properties of the leaf extract of Mimosa pudica Linn. Indian J Sci Technol 2016;9:1-6.

35. Muthukumaran P, Shanmuganathan P, Malathi C. In vitro antioxidant evaluation of Mimosa pudica. Asian J Pharm Res 2011;1:44-6.

36. Kamboj PR, Kalia AN. Evaluation of in-vitro (non and site specific) antioxidant potential of Mimosa pudica roots. Int J Pharm Pharm Sci 2011;3:497-501.

37. Immaculate AR, Rani VU. A comparative study on in vitro antioxidant and antibacterial activities of methanol extract from the leaves of Stachytarpheta indica (L) Vahl and Premna corymbosa Rottl. Int J Curr Pharm Res 2015;7:43-8 